\title{
Superplastic Creep of AuSn Eutectic Solder Alloy
}

\author{
by \\ J. W. Elmer and R. P. Mulay \\ Materials Engineering Division, Lawrence Livermore National Laboratory \\ Key Words: \\ Creep, Superplasticity, Grain Boundary Sliding, Coarsening, Strain Rate
}

\begin{abstract}
The large-strain tensile creep behavior of $\mathrm{Au}_{80} \mathrm{Sn}_{20}$ wt\% eutectic was studied at temperatures between $125^{\circ} \mathrm{C}$ and $200^{\circ} \mathrm{C}$. Constant load creep experiments were performed and a power law relationship was created from this data to predict creep as a function of stress and temperature with a best-fit stress exponent $n=2.1$ and activation energy for creep of $Q=148.4 \mathrm{~kJ} / \mathrm{mol}$. Results show that the favorable creep resistance of AuSn reduces considerably at temperatures above $125^{\circ} \mathrm{C}$, having $1000 x$ higher creep rate at $200^{\circ} \mathrm{C}$ than $125^{\circ} \mathrm{C}$. Of particular note is the observation of superplasticity in AuSn, with failure strains reaching $740 \%$ at $200^{\circ} \mathrm{C}$.
\end{abstract}

\section{Article}

AuSn solder is a high temperature eutectic solder with a melting point of $280^{\circ} \mathrm{C}$ that is used in high performance optoelectronics, power electronics, MEMS sensors, hermetic sealing, and other applications [1-3]. AuSn is lead-free, can be used without flux, and has favorable mechanical properties being a hard solder with good creep resistance relative to traditional soft solders such as SnPb alloys [4]. In addition, AuSn has good thermal and electrical conductivity, and high resistance to electromigration, which are important characteristics for high performance electronic applications [5].

AuSn is one of the more important lead-free high temperature hard solders due to its high strength and good creep resistance at conventional operating temperatures up to $125^{\circ} \mathrm{C}[1-3$, 5]. However, increasing demands are being placed on solder alloys in general to perform at even higher temperatures due to more extreme environments experienced in the automotive, aerospace, military and oil-exploration industries [5]. In addition, heat generation by the device itself due to miniaturization of microelectronics electronics, higher powers and higher switching speeds in power electronics, and higher average power laser and optoelectronic devices drives 
a need for higher temperature solders with creep resistance to $200^{\circ} \mathrm{C}$ [1-3]. These demands are further complicated by restrictions being placed on $\mathrm{Pb}$ containing solders, which severely limits the use of $\mathrm{Pb}$ in solders, creating a need for high temperature lead-free solders $[3,5]$.

In this study, the tensile creep behavior of AuSn is investigated in the $125^{\circ} \mathrm{C}$ to $200^{\circ} \mathrm{C}$, range, where very little experimental data exist. A constitutive model of creep rate as a function of stress and temperature is created, and observations of superplasticity of AuSn are reported. The results show that the favorable creep resistance of AuSn reduces considerably above $125^{\circ} \mathrm{C}$, displaying high creep rates and superplastic strains to $740 \%$ at $200^{\circ} \mathrm{C}$.

AuSn solder foil was purchased in the as rolled condition with dimensions of 50 um thick and 10 $\mathrm{mm}$ wide. The initial grain size of the foil was measured ot be $1.3 \mu \mathrm{m}$ based on an average of seven measurements made with a line intercept method from SEM images of the microstructure. Tensile dog-bone samples of two different geometries, illustrated in Fig. 1, were cut from the foil using a pulsed laser machining process. The longer gage length (GL) samples were used to measure creep strains up to $125 \%$ in a tensile test machine, while the shorter samples were used to explore the high strain, superplastic, behavior using a dead load creep setup. Tensile creep testing to $125 \%$ strain was carried at a constant load on a low 0.001 $35 \mathrm{~N}$ tensile test machine equipped with a forced air convection oven. Non-slip grips were fabricated to clamp the samples into the test fixture, and tests were performed at stresses from 0.5 to $100 \mathrm{MPa}$ (loads ranged from 0.1 to $25 \mathrm{~N}$ ). The creep stress was calculated by dividing the initial cross sectional area of the tensile sample by the applied load. Creep testing was carried out at four different temperatures of $125,150,175$ and $200^{\circ} \mathrm{C}$, strain was measured using crosshead displacement during the constant load controlled experiment. The creep strain rate was calculated from the slope of the strain (cross head displacement) vs. time plot taken over the initial mostly linear region of the creep curve at $20 \%$ strain. Note that measuring the creep rate at $20 \%$ is at a higher strain that normal, but seemed appropriate in these samples that achieved hundreds of percent elongations prior to failure. Tensile creep testing to large strains was carried out using a dead-load testing setup in an air furnace at temperatures up to $200^{\circ} \mathrm{C}$. Scribe lines were placed on the sample for strain verification. These tests allowed the samples to be strained more than $1000 \%$ prior to failure.

Metallurgical characterization was performed on the as received AuSn foil and on some of the creep tested samples using optical and electron optical methods. The samples were prepared for metallography and scanning electron microscopy (SEM) by sequentially grinding on SiC papers from US 600 to 1200 grit. Fine polishing was done using 3 um diamond paste followed by 0.1 um alumina. The final polishing step was carried out with 0.07 um colloidal silica. Etching of the samples was not required due to the high optical and electron optical contrast between the $\mathrm{Au}_{5} \mathrm{Sn}$ and AuSn phases present in the microstructure. SEM imaging in the backscattered 
mode and electron backscattered diffraction (EBSD) was carried out on a Philips FEG XL 30S SEM with a field emission gun. The SEM is equipped with an EBSD camera and a TSL data acquisition system.

The microstructure of the AuSn alloy foil in the as received condition is shown in Fig. 2a, and consists of two phases. From the equilibrium phase diagram [6, 7], we know that the eutectic mixture of two phases, $\mathrm{Au}_{5} \mathrm{Sn}(\zeta)$ and $\mathrm{AuSn}(\delta)$ are present. The $\zeta$ phase has an ordered hexagonal crystal structure which disorders to $\zeta^{\prime}$ above $190^{\circ} \mathrm{C}$, while the $\delta$ phase is also a hexagonal phase with different ordering than $\zeta$ phase $[6,7]$. In these SEM images, the $\mathrm{Au}_{5} \mathrm{Sn}$ appears bright in the backscattered mode due to the higher concentration of gold which causes more back scattered electrons, while the AuSn phase appears dark. Quantitative analysis of the two phase shows that the starting microstructure contains $32 \pm 8 \%$ AuSn, and $68 \pm 8 \% \mathrm{Au}_{5} \mathrm{Sn}$ by area, which matches what one would expect from the eutectic point on the AuSn phase diagram [6, 7]. The microstructure is comprised of a distribution of fine grains ranging from submicron to a few microns. Note that the term "grain size" will be used here to represent the average size of the $\delta$ and $\zeta$ heterophase boundaries. When heated at $200^{\circ} \mathrm{C}$ for 21 days the microstructure coarsens to interconnected grains with an average diameter of 3.5 um as shown in Fig. 2b. The extended heat treatment exceeds the maximum time at the highest temperature of any of the creep tests performed in this study, in order to give an upper limit of microstructure coarsening that may occur during creep testing.

Tensile creep tests under controlled load conditions were performed for sample configurations shown in Fig. 1. One resulting set of creep curves is shown in Fig. 3a, which was obtained at four different stresses and all at the lowest creep temperature of $125^{\circ} \mathrm{C}$. It can be seen that there is no clear region of primary creep, i.e. the creep rate constantly increase from the start to the end of the test. All of the samples in this set of experiments exceeded $100 \%$ strain to failure, indicating very large creep deformations even at the lowest temperature of $125^{\circ} \mathrm{C}$. From the creep curves, the creep rate was determined from the initial, mostly linear, portion of the curve up to a strain of $20 \%$.

The creep rate as a function of stress and temperature can be expressed by a power law relationship relating the steady state (SS) creep rate, $\dot{\varepsilon}_{\mathrm{ss}}$, to the steady state flow stress, $\sigma_{\mathrm{ss}}$, as follows [8]:

$$
\dot{\varepsilon}_{s s}=A \sigma_{s s}^{n} \exp (-Q / R T) \quad \text { eq. } 1
$$

where, $\mathrm{n}$ is the stress exponent, $\mathrm{Q}$ is the activation energy for creep, $\mathrm{A}$ is material and microstructure dependent constant, $\mathrm{R}$ is the gas constant, and $\mathrm{T}$ is the absolute temperature. The stress exponent can be determined from tests run at different stresses at a constant temperature, while $Q$ can be determined from tests run at a constant stress and different 
temperatures. The stress exponent, $n$, may further be a function of temperature or stress itself, and $Q$ may be a function of stress as different creep mechanisms become active [8]. Table 1 summarizes the experimental matrix for the 21 creep tests performed in this study, and was designed in such a way that $\mathrm{n}$ and $\mathrm{Q}$ could be determined for AuSn creep for the temperature range of 125 to $200^{\circ} \mathrm{C}$.

Figure $3 \mathrm{~b}$ plots creep rate versus stress on log-log coordinates for each of the four temperatures. The slopes of the best fit lines through each of the data sets gives the stress exponent, $\mathrm{n}$, which shows an increasing trend with temperature from 1.87 at $125^{\circ} \mathrm{C}$, to 2.7 at $200^{\circ} \mathrm{C}$. All of the $n$ values are less than 3 , which would suggest that creep is occurring by a grain boundary sliding (GBS) mechanism $[8,9]$. GBS is a creep mechanism found at temperatures above $0.5 T_{M}$, where $T_{M}$ represents the absolute melting temperature of the alloy, and in fine grained metals. For AuSn that melts at $280^{\circ} \mathrm{C}$, the temperature range of 125 to $200^{\circ} \mathrm{C}$ represents a homologous temperature, $\mathrm{T} / \mathrm{T}_{\mathrm{M}}$, range of 0.72 to 0.86 . Figure 2 shows that the starting microstructure has grain sizes less than $10 \mu \mathrm{m}$ even after sever coarsening heat treatment of 21 days at $200^{\circ} \mathrm{C}$. These conditions in AuSn favor GBS as the creep mechanism, which is known to be the principal mechanism for superplastic deformation to very large strains [8-11].

The coefficients for the power law creep expression given in eq. 1 were determined by finding the activation energy, $Q$, and then using this value to find a best fit value of $n$ for the temperature range of the data. Figure 4 a plots two sets of constant stress data creep rate data at 4 and $10.5 \mathrm{MPa}$ as a function of $1 / \mathrm{T}$, where the slope of these lines is the value of $-Q / R$ in eq. 1. From this data $\mathrm{Q}$ is measured to be $159 \mathrm{~kJ} / \mathrm{mol}$ at $4 \mathrm{MPa}$, and $137 \mathrm{~kJ} / \mathrm{mol}$ at $10.5 \mathrm{MPa}$ stress. The average value of $Q$ for these two stresses is $148.4 \mathrm{~kJ} / \mathrm{mol}$, which was then used to calculate the stress exponent $n$ given by the plot shown in Fig. $4 \mathrm{~b}$. In this plot all the data are fit to eq.1 on linearized coordinates, where the slope of the best fit line is equal to the best fit value of ' $n$ '. The result gives $n=2.1$, and show a good fit to the data with a least squares correlation coefficient of $R^{2}=0.9885$. The pre-exponential constant, $A$, is further determined from the intercept of the best-fit line with the $y$-axis in Fig. $4 b$, where $\ln A=26.4\left(A=2.9 \times 10^{11}\right)$. Other studies have measured $\mathrm{n}$ for AuSn at temperatures up to $125^{\circ} \mathrm{C}$, with values between 2.07 and $3.3[4,12,13]$. The stress exponent of $n=2.1$ measured here, for temperatures above $125^{\circ} \mathrm{C}$, falls within this same range.

The data above was gathered in the tensile creep machine that limited the maximum strain to about $125 \%$ for the long GL samples and about 500\% for the short GL samples shown in Fig.1. However, it was found that even some of the shorter GL samples reached the furnace limit without failing at $500 \%$ creep strain. To determine the maximum strain achievable before failure, a small creep rig was set up in an oven allowing for strains greater than $1000 \%$. 
Samples of the shorter geometry were placed at different temperatures and dead loaded, and the strain and time to failure were recorded. Table 2 summarizes these data, along with the highest strains recorded at each temperature, and results show that the failure strains increase with temperature, reaching $740 \%$ at $200^{\circ} \mathrm{C}$. Figure $1 \mathrm{c}$ shows the sample strained to $740 \%$ with an untested sample for comparison, which clearly demonstrates superplastic creep behavior in AuSn. Superplastic deformation of $500 \%$ was also observed in the precoarsened microstructure, and it is interesting to note that the precoarsened sample had a creep rate of approximately $50 \%$ of the as received sample at $200^{\circ} \mathrm{C}$ The lower creep rate is associated with the larger grains size of the precoarsened sample (3.5 vs. $1.3 \mu \mathrm{m}$ ) and associated lower grain boundary volume, and gives some indication of the effect of initial grain size on creep rate in AuSn.

Superplasticity has been observed in other low melting point solder alloy systems containing $\mathrm{Pb}, \mathrm{In}, \mathrm{Bi}$, and $\mathrm{Sn}$ [11], but not in the AuSn system to the author's knowledge. Characteristics of superplastic alloys are that they have a fine and stable microstructure with grain sizes typically less than $10 \mu \mathrm{m}$, a stress exponent between 2 and 3, negligible primary creep, and activation energies similar to grain boundary diffusion [8-11]. The AuSn alloy has many of these characteristics, where it has a stress exponent $n=2.1$ in this temperature range, no measurable primary creep, a starting microstructure with grain sizes of a few microns or less and reasonably stable microstructure with heterophase grain sizes less than $10 \mu \mathrm{m}$ even after extended heat treating at a homologous temperature of 0.86 . In addition, the two phases that form during AuSn eutectic solidification are both ordered intermetallic hexagonal phases, each with significantly higher melting points than the eutectic temperature. The $\delta$ phase, AuSn, has a melting point maximum at $419^{\circ} \mathrm{C}$, while the $\zeta^{\prime}$ phase, $\mathrm{Au}_{5} \mathrm{Sn}$, forms a peritectic at $521^{\circ} \mathrm{C}[6]$. The higher melting points, and high hardness of these phases of over $1 \mathrm{GPa}$ [14], may provide stability to coarsening of the microstructure compared to non-intermetallic phase microstructures such as those formed in SnPb solder alloys.

The measured activation energy of $Q=148.4 \mathrm{~kJ} / \mathrm{mol}$ is higher than what would be expected for grain boundary diffusion, being similar to the activation energy for tracer impurity lattice diffusion of $\mathrm{Sn}$ in Au of $143 \mathrm{~kJ} / \mathrm{mol}$ at high temperatures, and considerably higher than diffusion of $\mathrm{Au}$ in $\mathrm{Sn}$ of 46-74 kJ/mole at lower temperatures [15]. Other researchers have measured activation energies for creep of the AuSn alloy, at $102 \mathrm{~kJ} / \mathrm{mol}$ [4], and $79.3 \mathrm{~kJ} / \mathrm{mol}$ [13], so there appears to be a wide variation in the measured $Q$ for AuSn creep. Some possible differences between the results of the different studies are related to the starting microstructures and testing conditions. Aside from the higher temperatures used in this study, Zheng et al. [4] performed tensile creep studies on cast AuSn bulk samples with $\mathrm{mm}$ sized dimensions, while Bourcier et al. (referenced in [13]) performed compression tests on cast bulk samples; both studies having starting microstructures and test conditions being different than the tensile 
experiments performed here on thin rolled foils. The effects of starting microstructure on creep rate and the measured activation energy of creep will require additional studies, and are important in understanding the rate controlling mechanisms for creep in AuSn.

In summary, steady state creep rates for AuSn were measured at temperatures between 125 and $200^{\circ} \mathrm{C}$, and were fit to a power law relationship with the following results for $\sigma_{\mathrm{ss}}(\mathrm{MPa}), \dot{\varepsilon}_{\mathrm{ss}}$ $\left(\mathrm{s}^{-1}\right)$, and $\mathrm{Q}(\mathrm{kJ} / \mathrm{mol})$ :

$$
\dot{\varepsilon}_{S S}=2.9 \times 10^{11} \sigma_{S S}^{2.1} \exp (-148.4 / R T) \quad \text { eq. } 2
$$

The measured stress exponent $n=2.1$ suggests that grain boundary sliding is the dominant creep mechanism for AuSn in this temperature range [4, 8, 9]. Note that Zhang et al. [4] have also measured similar stress exponents in bulk cast AuSn samples at temperatures up to $125^{\circ} \mathrm{C}$, and have suggested grain boundary sliding as the dominant creep mechanism. Although a stress exponent of $n=2.1$ was measured in this study, it is important to note that these experiments were performed at relatively high stresses (1-100 MPa), and that these stresses may be above the threshold stress where a transition in stress exponents in superplastic alloys can occur [16]. Additional experimental work at lower stresses, and additional characterization work on the microstructures from this study would provide a more definite identification of the creep mechanism in AuSn.

The activation energy for creep measured in this study of $148.4 \mathrm{~kJ} / \mathrm{mol}$ is similar to bulk diffusion of $\mathrm{Sn}$ in Au at high temperatures. The steady state creep rate of AuSn was shown to increase $\sim 1000$ x between $125^{\circ} \mathrm{C}$ and $200^{\circ} \mathrm{C}$, with high elongations to failure that increase with temperature. Superplasticity was observed In AuSn with elongations greater than $100 \%$ strain for all of the conditions studied, and elongations as high as $740 \%$ were demonstrated at a temperature of $200^{\circ} \mathrm{C}$. Superplasticity in AuSn may have implications beyond the traditional solder interconnections used in the microelectronics industry. For example, high creep rate superplastic forming may be developed for new types of joints and attachments in the high reliability electronics industry and elsewhere.

\section{Acknowledgment}

This work was performed under the auspices of the U.S. Department of Energy by Lawrence Livermore National Laboratory under Contract DE-AC52-07NA27344. The authors would like to thank the following LLNL employees: Dr. Amanda Wu for assistance and calibration of the creep testing machine, Ms. C. Evans and Mr. J. Embree for metallographic sample preparation, Mr. J. Lotscher for dead load creep testing, Ms. M. LeBlanc for assistance with mechanical test fixturing, and Mr. E. Ziebarth for laser machining of the test samples. 


\section{References}

1. V. R. Manikam and K Y Cheong, "Die Attach Materials for High Temperature Applications: A Review," IEEE Trans. on Components, Packaging and Manufacturing Technology, 1(4), pp. 457478, 2011.

2. G. Zeng, S. McDonald, and K. Nogita, "Development of High-Temperature Solders: Review," Microelectronics Reliability, 52, pp. 1306-1322, 2012.

3. V. Chidambaram, J. Hattel, J. Hald," Design of Lead-Free Candidate Alloys for High-Temperature Soldering Based on the Au-Sn System," Materials and Design 31, pp. 4638-4645, 2010.

4. G. S. Zhang, H. Y. Jing, L. Y. Xu, J. Wei, Y. D. Han, "Creep Behavior of Eutectic 80Au/20Sn Solder Alloy," J. Alloys and Compounds, 476, pp. 138-141, 2009.

5. F. W. Gayle et al., "High Temperature Lead-Free Solder for Microelectronics," J. of Metals, 53, pp. 17-21, 2001.

6. T. B. Massalski, Binary Phase Diagrams, $2^{\text {nd }}$ Edition, ASM International, 1990.

7. J. Ciulik, and M. R. Notis," The Au-Sn Phase Diagram, J. Alloys and Compounds, 191, pp. 71-78, 1993.

8. M. E. Kassner, Fundamentals of Creep in Metals and Alloys, third edition, Elsevier, 2015.

9. T. G. Neih, J. Wadsworth, and O. D. Sherby, Superplasticity in Metals and Ceramics, Cambridge University Press, 1997.

10. Edington, Jeffrey William, K. N. Melton, and C. P. Cutler. "Superplasticity."Progress in Materials Science 21.1 (1976): 61-170.

11. Z. Mei and J. W. Morris, Jr., "Superplastic Creep of Low Melting Point Solder joints," J. Electronic Materials, 21(4), pp. 401-407, 1992.

12. T. Namazu, H. Takemoto, S. Inoue, "Tensile and Creep Characteristics of Sputtered Gold Tin Eutectic Solder Film Evaluated by XRD Tensile Testing," Sensors and Materials, 22, pp. 13-24, 2010.

13. H. S. Morgan, "Thermal Stresses in Layered Electrical Assemblies Bonded with Solder," Trans. AIME, V113, pp. 350-354, Dec. 1991.

14. R. R. Chromik, D-N Wang, A. Shugar, L. Limata, M. R. Notis, and R. P. Vinci," Mechanical Properties of Intermetallic Compounds in the Au-Sn System," J. Mater. Res., 20(8),p. 2161, 2005.

15. Smithell's Metals Reference Book, $8^{\text {th }}$ ed., Edited by W. F. Gale and T. C. Totemeier, Elsevier, 2004.

16. F. A. Mohamed, "Interpretation of superplastic flow in terms of a threshold stress," J. Mater Sci, 18, p. 562, 1983. 


\section{Tables}

Table1: Matrix of test conditions and measured creep rates for the 21 tests performed in this investigation, where the SS creep rate is measured at $20 \%$ strain.

\begin{tabular}{|c|c|c|}
\hline $\begin{array}{c}\text { Temperature } \\
\left({ }^{\circ} \mathrm{C}\right)\end{array}$ & $\begin{array}{c}\text { Creep Stress } \\
(\mathrm{MPa})\end{array}$ & $\begin{array}{c}\text { SS Creep Rate } \\
\left(\mathrm{s}^{-1}\right)\end{array}$ \\
\hline 125 & & $8.96 \mathrm{E}-05$ \\
\hline 125 & 89.7 & $6.16 \mathrm{E}-05$ \\
\hline 125 & 76.9 & $5.28 \mathrm{E}-05$ \\
\hline 125 & 65.2 & $3.21 \mathrm{E}-05$ \\
\hline 125 & 47.0 & $9.77 \mathrm{E}-06$ \\
\hline 125 & 25.8 & $2.44 \mathrm{E}-06$ \\
\hline & 12.4 & $2.57 \mathrm{E}-04$ \\
\hline 150 & & $8.47 \mathrm{E}-05$ \\
\hline 150 & 30.0 & $3.13 \mathrm{E}-05$ \\
\hline 150 & 23.4 & $9.43 \mathrm{E}-06$ \\
\hline 150 & 11.6 & $3.10 \mathrm{E}-06$ \\
\hline 150 & 6.7 & $3.38 \mathrm{E}-07$ \\
\hline 150 & 3.8 & $2.48 \mathrm{E}-04$ \\
\hline & 1.9 & $6.90 \mathrm{E}-05$ \\
\hline 175 & & $2.31 \mathrm{E}-05$ \\
\hline 175 & 10.3 & $1.08 \mathrm{E}-05$ \\
\hline 175 & 5.9 & $3.61 \mathrm{E}-06$ \\
\hline 175 & 4.2 & \\
\hline 175 & 2.8 & $3.85 \mathrm{E}-04$ \\
\hline 200 & 1.9 & $1.26 \mathrm{E}-04$ \\
\hline 200 & & $3.95 \mathrm{E}-05$ \\
\hline 200 & 4.5 & $9.42 \mathrm{E}-06$ \\
\hline 200 & 2.6 & \\
\hline & 1.6 & 1.2 \\
\hline
\end{tabular}

Table 2: Results of the highest strains to failure at each of the four temperatures. Average creep rates are based on failure time, and ranges are given for the dead-loaded samples based on uncertainty of failure time.

\begin{tabular}{|c|c|c|c|c|}
\hline $\begin{array}{c}\text { Stress } \\
(\mathrm{MPa})\end{array}$ & $\begin{array}{c}\text { Temperature } \\
\left({ }^{\circ} \mathrm{C}\right)\end{array}$ & $\begin{array}{c}\text { Strain to failure } \\
(\%)\end{array}$ & $\begin{array}{c}\text { Time to Failure } \\
(\text { days })\end{array}$ & $\begin{array}{c}\text { Average creep rate } \\
\left(\mathrm{s}^{-1}\right)\end{array}$ \\
\hline 1.5 & 200 & 740 & $3-4$ & $2.5 \times 10^{-5} \pm 0.3 \times 10^{-5}$ \\
\hline 1.5 & 200 & $545^{*}$ & $4-7$ & $1.2 \times 10^{-5} \pm 0.25 \times 10^{-5}$ \\
\hline 1.9 & 175 & 520 & $8-9$ & $6.8 \times 10^{-6} \pm 0.38 \times 10^{-6}$ \\
\hline 11.6 & 150 & 370 & $1-2$ & $2.3 \times 10^{-5} \pm 0.58 \times 10^{-5}$ \\
\hline 47.0 & 125 & 240 & 0.27 & $1.01 \times 10^{-4}$ \\
\hline
\end{tabular}

* Sample pre-coarsened 21 days at $200^{\circ} \mathrm{C}$ prior to creep testing. 


\section{Figures}

a)

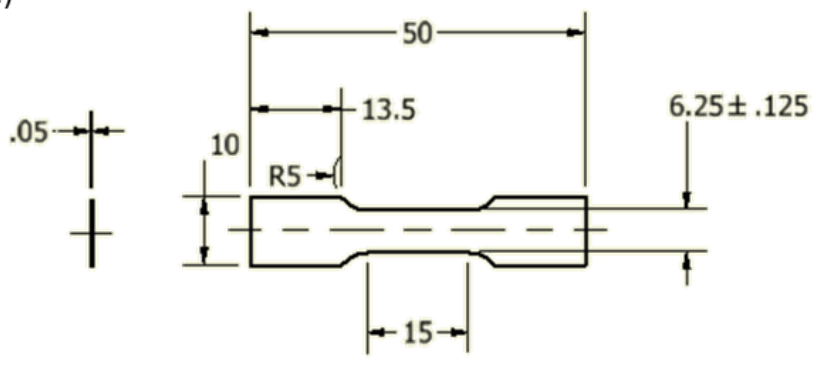

b)

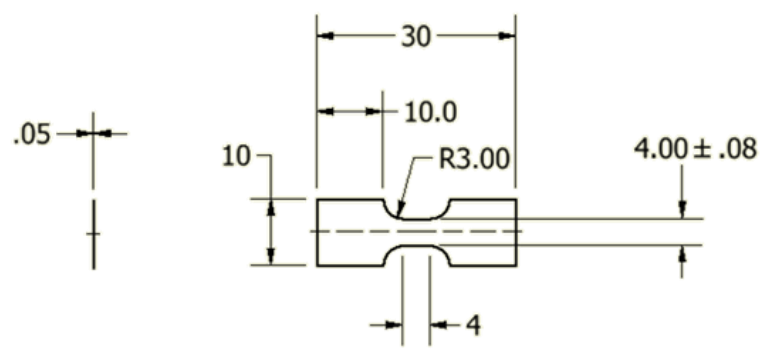

c)

Figure 1: Tensile, dog bone shaped, samples used for creep tests. a) $15 \mathrm{~mm}$ long gage length specimen, b) $4 \mathrm{~mm}$ short gage length specimen, and c) photograph of a short gage length sample before and after testing with creep strain of $750 \%$ at $200^{\circ} \mathrm{C}$

a)

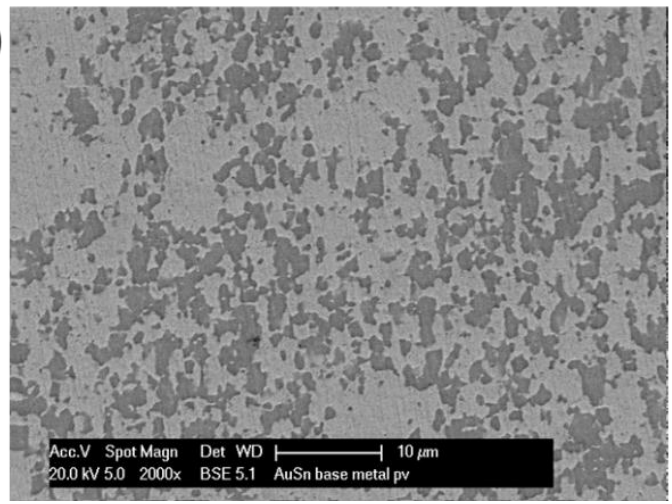

b)

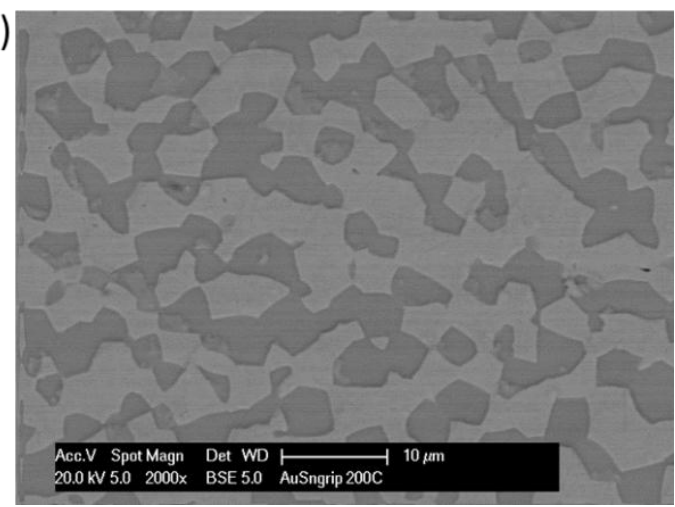

Figure 2: Backscattered SEM images of the microstructure of AuSn in: a) as received foil with $1.3 \mu \mathrm{m}$ average grain size, and $\mathrm{b}$ ) after heat treating at $200^{\circ} \mathrm{C}$ for 21 days with $3.5 \mu \mathrm{m}$ average grain size. The rolling direction of foils and direction of tensile creep tests is vertical in both micrographs. 


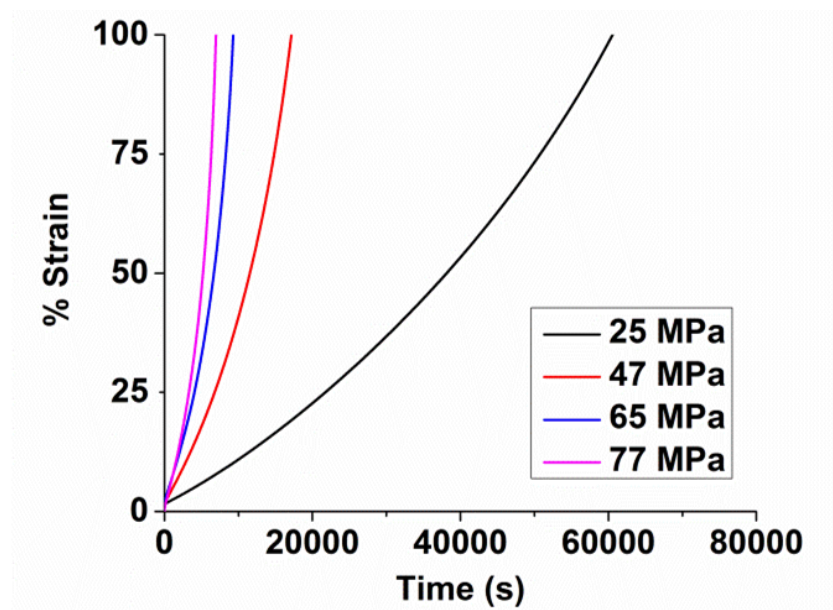

(a)

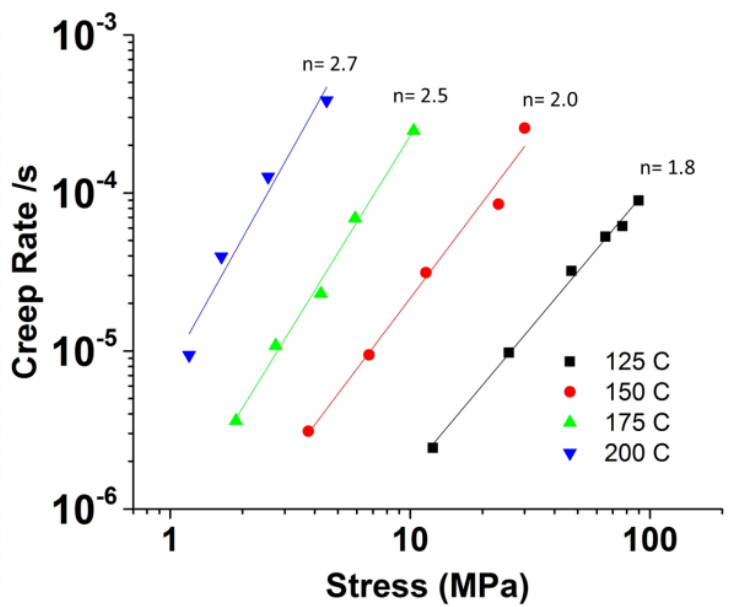

(b)

Figure 3: a) Creep curves of AuSn at $125^{\circ} \mathrm{C}$, truncated at $100 \%$ strain, and b) creep rates of AuSn between 125 and $200^{\circ} \mathrm{C}$. The power law stress exponent, $n$, is indicated for each temperature.

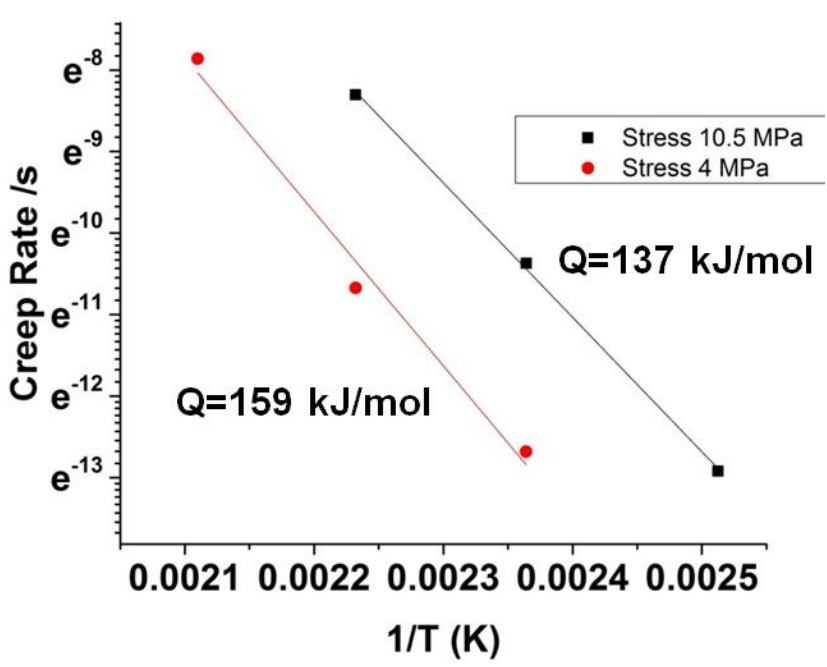

(a)

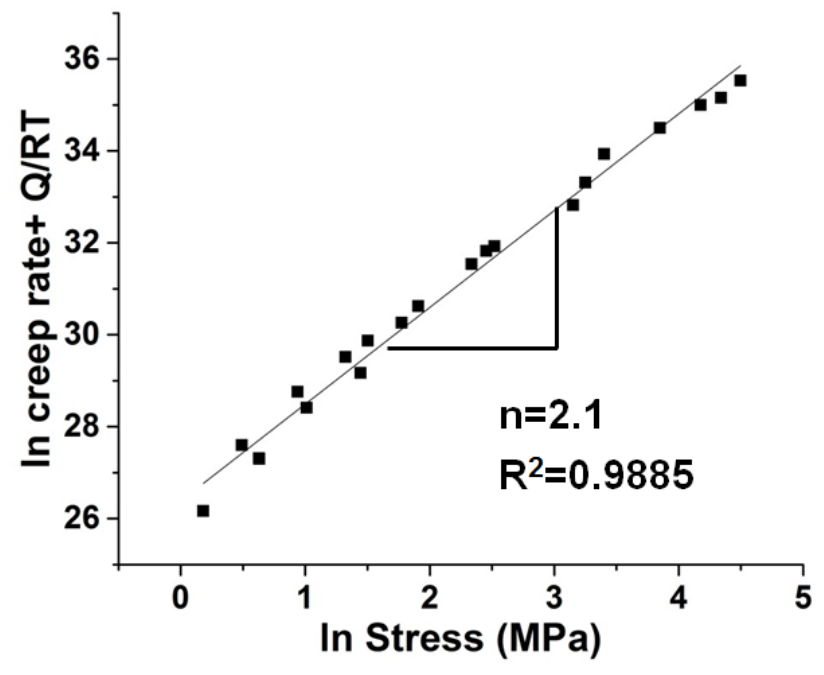

(b)

Figure 4: a) Creep rate plotted on a logarithmic scale vs. the reciprocal of the absolute temperature to measure $Q$ at 4 and $10.5 \mathrm{MPa}$. b) All of the creep data plotted on linearized coordinates vs. In stress using the average $Q$ value. The slope of this line is the best fit ' $n$ ' value for the data set. 


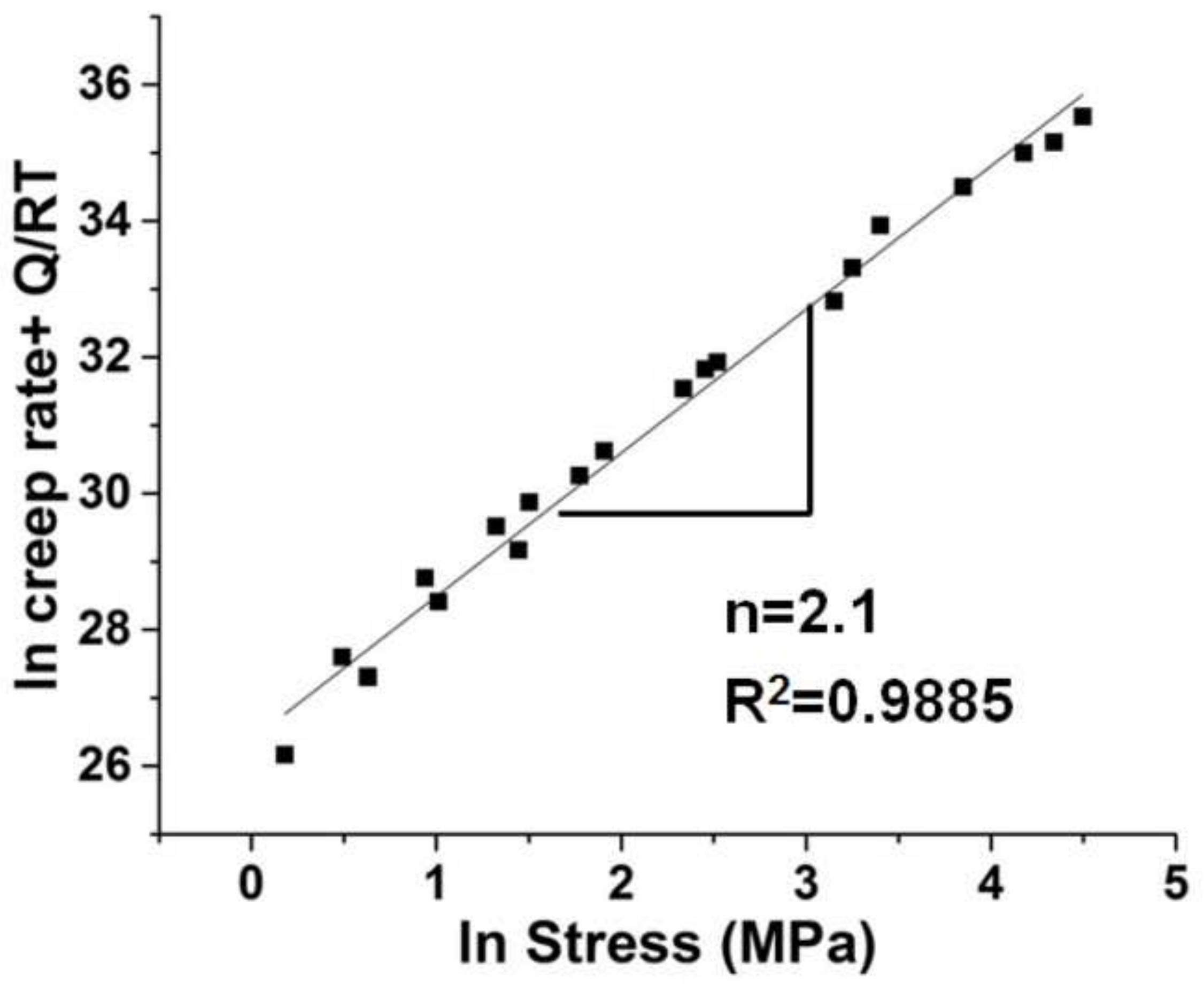

